\title{
Entre a Commoditycidade e a pesquisa engajada
}

Não é de hoje que diferentes autores vêm manifestando a ostensiva atuação da lógica mercadológica regulando aquilo que deve ser produzido e publicado no ensino superior, “[...] tendência que já se revela hegemônica” (BIANCHETTI; SGUISSARDI, 2017, p. 78) e denota o movimento de Commoditycidade não somente das pesquisas realizadas, mas da universidade como um todo. Nesse sentido, os periódicos sobrevivem no paradoxo que coaduna fomento daquilo que é relevante e resposta às necessidades específicas de um sistema de avaliação.

Entretanto, a organização, proposição e publicação de seções temáticas, como tem sido prática nos últimos números da Roteiro, vêm tornando menor o fardo de lidarmos com o referido paradoxo, trazendo para o centro da discussão temas e problemas que apertam o laço do engajamento político, teórico e social que se espera das revistas, especialmente em Educação.

0 nosso volume 44, n. 2, da Roteiro conta com a seção temática Educação e Diferença: diálogo e perspectivas, que apresenta 10 diferentes produções escritas e foi organizada pelos professores Jaqueline Barbosa da Silva, Everaldo Fernandes da Silva e Eduardo Jorge da Silva. A preocupação fundamental estabelecida por eles é reafirmar a demanda de uma organização da escola para indígenas e quilombolas que se ancore nas práticas educativas e em organizações curriculares que sejam mais específicas e superem o arquétipo educacional eurocêntrico, ainda muito estrutural na educação brasileira.

Além disso, contamos com uma entrevista realizada com Joana Peixoto, duas resenhas e seis artigos de demanda contínua. A capa dá lugar à fotografia de Leo Otero, que problematiza o conflituoso momento de esvaziamento de políticas públicas de proteção às comunidades marginalizadas por que estamos passando.

Desejamos a todos uma boa leitura!

Priscila Monteiro Chaves

Nadiane Feldkercher

Marilda Schneider 


\section{REFERÊNCIA}

BIANCHETTI, L.; SGUISSARDI, V. Da universidade à Commoditycidade: ou de como e quando, se a educação/formação é sacrificada no altar do Mercado, o futuro da universidade se situaria em algum lugar do passado. Campinas, SP: Mercado de Letras, 2017. 